JOSÉ ALBERTO ALLENDE PÉREZ DE ARCE |

\title{
PROCEDENCIA DEL RECURSO DE QUEJA RESPECTO DE LA CONDENA Y TASACIÓN DE COSTAS
}

\author{
ADMISSIBILITY OF THE COMPLAINT MOTION AGAINST \\ THE IMPOSITION AND ASSESSMENT OF \\ THE LITIGATION COSTS
}

\begin{tabular}{|c|c|}
\hline \multicolumn{2}{|c|}{ ARTÍCULO INÉDITO DE INVESTIGACIÓN } \\
\hline CÓMO CITAR ESTE ARTÍCULO (CHICAGO) & $\begin{array}{l}\text { Allende Pérez de Arce, José Alberto. "Pro- } \\
\text { cedencia del recurso de queja respecto de } \\
\text { la condena y tasación de costas". } \\
\text { Revista de Derecho Aplicado } \\
\text { LLM UC } 4 \text { (20I9). } \\
\text { doi: } \text { Io.77 }_{4} / \text { rda.o.4.2672. }\end{array}$ \\
\hline REVISTA DE DERECHO APLICADO LLM UC & $\begin{array}{l}\text { Número } 4 \\
\text { Diciembre } 2019 \\
\text { ISSN: } 245^{2-4344}\end{array}$ \\
\hline & $\begin{array}{l}\text { Recepción: }{ }_{4} \text { de septiembre, } 2019 \\
\text { Aceptación: }{ }_{4} \text { de diciembre, } 2019\end{array}$ \\
\hline
\end{tabular}




\section{Resumen}

En este trabajo se analizan los mecanismos que existen para que la parte vencida en juicio, que fue condenada al pago de las costas, impugne tanto la condena en sí como la valorización de las costas que haga luego el tribunal. En ese contexto, se analiza con detención la procedencia del recurso de queja ante la Corte Suprema, y las otras posibilidades con las que cuenta dicho tribunal para revisar tales decisiones.

Palabras clave: Condena en costas, recurso de queja, admisibilidad.

\section{Abstract}

In this work we analyze the mechanisms available for the defeated party that was sentenced to assume the litigation costs to challenge both the decision imposing the sanction, and the assessment of those costs by the Court. In that context, special emphasis is given to the admissibility of the complaint motion before the Supreme Court, as well as to the other possibilities that exist to have those decisions reviewed by that same Court.

Keywords: Litigation costs, complaint motion, admissibility. 


\section{José Alberto Allende Pérez de Arce}

Allende Bascuñán y Cía.

Santiago, Chile

jaallende@abcia.cl
José Alberto Allende Pérez de Arce es abogado, licenciado en Derecho con distinción máxima por la Universidad de Los Andes, Chile y Magíster en Derecho (LLM) por University College de Londres. Asociado en Allende Bascuñán y Cía. Es autor de "El fortalecimiento de la conciliación como mecanismo para descongestionar los tribunales civiles de justicia”, en Revista de Derecho 32, n. 1 (2019), y "Tribunales civiles en línea: Una propuesta para introducirlos sin afectar el derecho a acceder a la justicia de aquellos que no están conectados a internet”, en Revista Chilena de Derecho y Tecnología 8, n. ${ }^{\circ} 1$ (2019).

José Alberto Allende Pérez de Arce is a lawyer, graduated in Law with maximum distinction from the Universidad de Los Andes, Chile and Master in Law (LLM) from University College London. Associate in Allende Bascuñán y Cía. He is the author of "El fortalecimiento de la conciliación como mecanismo para descongestionar los tribunales civiles de justicia”, in Revista de Derecho 32, No. 1 (2019), and "Tribunales civiles en línea: Una propuesta para introducirlos sin afectar el derecho a acceder a la justicia de aquellos que no están conectados a internet", in Revista Chilena de Derecho y Tecnología 8, No. 1 (2019). 


\section{INTRODUCCIÓN}

Poco se ha escrito en nuestro país respecto de la condena en costas. Posiblemente ello se debe a que las normas que la regulan son claras, y que su interpretación y aplicación no exige mayor esfuerzo. Otra explicación vendría dada por el hecho de que en general las condenas en costas no involucran sumas importantes de dinero, ya que los tribunales son cautos a la hora de regularlas.

No obstante lo anterior, en el último tiempo hemos sabido de casos en los que los sentenciadores han impuesto a la parte que resultó vencida condenas bastante más elevadas de lo normal. De hecho, este año, en un caso concreto al que nos referiremos en este trabajo, se condenó a una parte al pago de costas por varios cientos de millones de pesos, lo que se alejó de las moderadas sumas que por lo general se aplican ${ }^{1}$.

El hecho de que aparezcan elevadas condenas en costas nos ha llevado a preguntarnos sobre los mecanismos con los que cuenta la parte condenada para oponerse a ellas o impugnar su monto. Si bien existen procedimientos para oponerse tanto a la condena en costas como a la regulación de las mismas, hay ciertos casos en los que los pasos a seguir no son tan claros, sobre todo cuando se trata de decisiones adoptadas en instancias superiores.

Lo anterior ha llevado a que sean cada vez más los casos en los que los litigantes condenados en costas intentan revertir esa condena, o el monto de la misma, por medio del recurso de queja. Sin embargo, y según analizaremos, de la revisión de esos casos queda en evidencia que la gran mayoría de esos recursos son rechazados o declarados inadmisibles, lo que aumenta la incertidumbre respecto de las posibilidades que tiene la parte afectada para impugnar las costas.

Probablemente a este tema no se le dará mayor importancia si la condena en costas es de baja entidad. En ese caso, lo que ocurrirá es que más allá del mal rato o de la sensación de injusticia, la parte condenada no hará nada respecto de ella, y se limitará a pagarla. Pero la situación cambia si las costas son elevadas, y más aún si son desproporcionadas. No parece razonable que una condena que signifique una porción importante del monto que fue objeto del juicio sea aplicada por un tribunal y no pueda ser objeto de revisión alguna por parte de un tribunal superior.

Es por ello que en este trabajo expondremos los distintos medios de impugnación con los que cuenta la parte que resultó condenada en costas, tanto para oponerse a la condena misma como para objetar su regulación, y luego analizaremos la posibilidad de interponer el recurso de queja con esos mismos objetivos. Dado que la condena en costas

1 Eustaquio Martínez Martínez, "Las costas judiciales”, Revista del Abogado, i999. 
y la regulación de las mismas ocurre en momentos procesales distintos, y por medio de resoluciones distintas, el tratamiento de una y otra es diferente.

Según se explicará, creemos que la condena en costas sigue la misma suerte que la sentencia en la cual se inserta, por lo que dicha condena será impugnable en igual medida, y por los mismos medios, que la sentencia a la que accede. Por lo tanto, si la sentencia es susceptible de ser revisada por medio del recurso de queja, la condena en costas también lo será.

Respecto de la regulación de las costas (la determinación del monto, según explicaremos), el recurso de queja no sería procedente, puesto que la resolución que pronuncia un tribunal de segunda instancia respecto de su objeción no tiene la naturaleza jurídica que exige el artículo 545 del Código Orgánico de Tribunales.

A pesar de lo anterior, existen otros mecanismos para lograr que la Corte Suprema revise y eventualmente corrija una condena en costas, cuando una Corte de Apelaciones - o un panel arbitral de segunda instancia-, al pronunciarse prudencialmente respecto de ellas, fije una suma que sea evidentemente excesiva y desproporcionada, con lo que cometería una falta o abuso grave.

\section{SOBRE LAS COSTAS}

\section{I. Origen y objetivo de las costas}

Siguiendo su origen etimológico, la palabra costas está asociada a los gastos en los que incurren las partes para llevar adelante un procedimiento judicial. Si bien lo normal es que cada parte pague sus propios costos, el tribunal puede asignar el pago del total de ellas a la parte que resultó por completo vencida en el juicio. Esto último es lo que se conoce como la "condena en costas".

El origen de esta condena la encontramos en el derecho romano. Primero, como una garantía que debían entregar las partes de que actuarían de forma correcta en el juicio, sin abusar del proceso, y luego, como una forma de radicar en los particulares los costos que involucraba para el sistema que estos persiguieran sus derechos a través de los tribunales. Como señala Valiño:

El derecho romano se preocupó en etapas más tempranas por la represión del comportamiento emulativo en el curso del proceso, estimulando la creación de diversos expedientes que permitieran su sanción. En este orden de cosas, la actividad pretoria actuó decisivamente al requerir a las partes, como presupuesto para el acceso al proceso, una serie de garantías y juramentos, dirigidos a asegurar tanto la buena marcha del proceso como la consecución de su finalidad natural. 
Sin embargo, en derecho romano el nacimiento de la condena en costas surge con posterioridad en el tiempo, por cuanto es, ante todo, una consecuencia de la burocratización de la administración de justicia y la atribución al ciudadano de la responsabilidad de asumir, a su costa, aquellos gastos que se originan cuando alguien intenta obtener tutela de un derecho propio ${ }^{2}$.

Dicha reseña histórica refleja una de las principales discusiones que existe en torno a esta institución procesal, y que se refiere a la naturaleza jurídica de la condena en costas. Para Anabalón, es una sanción procesal que aplica el juez a aquel litigante que provocó un procedimiento sin tener razón alguna para hacerlo ${ }^{3}$. Para Chiovenda, en tanto, es un crédito o derecho que adquiere la parte demandada respecto de su contraparte, cuando esta resultó por completo vencida ${ }^{4}$. Finalmente, Romero destaca la labor que cumplen las costas como un límite en el ejercicio de la acción, al producir un desincentivo económico para aquel que pretende litigar sin fundamentos ${ }^{5}$.

Creemos que en nuestro ordenamiento procesal civil la condena en costas agrupa las tres opciones anteriores $^{6}$. Su elemento sancionatorio es claro, y así lo refleja, por ejemplo, el hecho de que sea denominada como una "condena", y que el mensaje del Código de Procedimiento Civil se refiera a ella como un "correctivo". En ese sentido, el Tribunal Constitucional ha declarado que "la condena en costas forma parte de las declaraciones que se contienen en la sentencia y que ponen término al procedimiento, imponiendo cargas a quien el Tribunal estima que ha litigado en forma desleal o que carece de motivo plausible para hacerlo"'. Asimismo, en la práctica solo se sanciona en costas a la parte que resultó enteramente vencida, y que a juicio del tribunal no tuvo motivo plausible para litigar. En efecto, si bien el artículo 144 del Código de Procedimiento Civil dispone que la parte que

2 Alejandro Valiño Arcos, "Algunos aspectos relacionados con la imposición de costas en el proceso civil en el derecho comparado". Revista Chilena de Derecho 29, n. ${ }^{\circ}$ ( (2002): I 47 .

3 Carlos Anabalón Sanderson, Tratado práctico de derecho procesal civil chileno (Santiago: Ediciones Universidad de Chile, I944), I74. Señala el autor: "La condenación en costas, no es una solicitud que sea ni puede ser, por su naturaleza una acción o excepción, sino sencillamente, una sanción impuesta por la ley al litigante que actúa sin razón ni justicia, de modo que dicha petición escapa al fondo de la decisión judicial, por no formar parte intrínsecamente del asunto controvertido".

4 José Chiovenda, Curso de derecho procesal civil (Ciudad de México: Harla, I997), 502.

5 Alejandro Romero Seguel, Curso de derecho procesal civil: La acción y la protección de los derechos (Santiago: Thomson Reuters, 20I7), 23I.

6 La condena en costas está regulada en el título I 4 del Código de Procedimiento Civil.

7 Tribunal Constitucional, rol I.557, I 4 de abril de 20 II. 
sea vencida totalmente en un juicio o en un incidente será condenada al pago de las costas, acto seguido la misma norma faculta al tribunal a eximir de su pago a la parte en cuestión, si a su juicio tuvo motivos plausibles para litigar. Por lo tanto, esta condena no solo tiene un componente objetivo (resultar enteramente vencido), sino también otro subjetivo que debe apreciar de manera prudencial el tribunal, lo que confirma su carácter de sanción.

También es clara la naturaleza de crédito o derecho pecuniario que tienen las costas para el litigante victorioso, puesto que el monto que se determine irá en su único beneficio, al punto que tiene derecho a cobrarlo judicialmente como cualquier otra obligación pecuniaria.

Por último, el rol de desincentivo para que litigantes temerarios abusen del procedimiento es igual de claro. Si bien es cierto que tradicionalmente la tasación de costas en Chile es baja y no se condice con los costos reales que tuvo para las partes litigar, en el último tiempo han ido apareciendo fallos en los que los tribunales se aventuran con condenas más altas ${ }^{8}$, antecedente que sin duda deberá ser considerado por una persona que está en la duda de si especular o no en tribunales.

Así las cosas, es clara la triple finalidad que tiene la condena en costas en nuestro ordenamiento jurídico, al ser al mismo tiempo una sanción para el vencido, un crédito para el vencedor y un desincentivo para todo aquel que pretenda usar de manera infundada el aparato judicial.

\subsection{De los tipos de costas}

En nuestro ordenamiento procesal civil las costas se dividen en personales y procesales (artículo 139 del Código de Procedimiento Civil). Las costas procesales son aquellas que se generan en la tramitación del proceso, lo que incluye los cobros de los receptores judiciales, el pago de copias, exhortos, estampillas o impuestos, entre otros ${ }^{9}$. Las costas personales, por su parte, corresponden a los honorarios de las personas que intervinieron en la controversia, como los abogados de las partes y los peritos.

8 Por ejemplo, en el caso La Rosa de Sofruco con Exportadora (rol C-337-20I4) se tasaron las costas personales del juicio en \$ 50 millones. En la causa Guínez con Díaz (rol 62-2012), la Corte de Apelaciones de Chillán confirmó una sentencia de primer grado que fijó las costas en la suma de \$ 9 millones. Finalmente, en la causa Anglo American Sur S.A. con Tranex Limitada (rol 5.92I-20I9), un Tribunal Arbitral de segunda instancia condenó a la parte vencida a pagar la suma de 55.500 UF en costas, según consta en expediente sobre recurso de queja tramitado ante la Corte Suprema.

9 Muchos de estos costos han ido cayendo en desuso con la entrada en vigencia de la Ley de Tramitación Electrónica. 
La distinción entre ambos tipos de costas es importante para este estudio, por la forma en que son determinadas unas y otras. Mientras las costas procesales son tasadas por el secretario del tribunal considerando solo aquellas diligencias que fueron útiles para la resolución del asunto (artículo 140 del Código de Procedimiento Civil), las costas personales son reguladas de manera prudencial por el tribunal, lo que implica que existe una mayor discreción y libertad de parte de este para su determinación.

Es precisamente esta mayor discrecionalidad y libertad en la determinación de las costas personales la que ha llevado a que de vez en cuando se impongan millonarias sanciones a las partes que resultan totalmente vencidas en juicio. De hecho, esas altas sumas siempre son determinadas como costas personales, y no como costas procesales. Asimismo, es esa discrecionalidad la que a nuestro juicio exige que en ciertos casos la condena en costas pueda ser revisada por la Corte Suprema.

\subsection{Del momento y forma en que se imponen las costas}

Por último, la condena en costas se materializa con la dictación de la resolución judicial que la impone, sea que se trate de la sentencia definitiva, y por lo tanto se refiera a las costas del juicio completo, o de una interlocutoria, cuando se trate de un incidente en particular. Como señala Chiovenda, "la obligación de las costas no surge durante la litis [...] Solo en el momento de fallarse sobre la demanda, esto es, cuando se determina el vencimiento, nace no solo el derecho del vencedor a las costas, sino el deber del juez de condenar al derrotado en las mismas" ${ }^{10}$.

\section{SOBRE EL RECURSO DE QUEJA}

\section{I. La regulación del recurso de queja}

El recurso de queja se encuentra regulado en el título 16 del Código Orgánico de Tribunales, denominado "De la jurisdicción disciplinaria y de la inspección y vigilancia de los servicios judiciales”.

El artículo 545 del Código dispone que este recurso tiene por única finalidad corregir las faltas o abusos graves cometidos por los tribunales en la dictación de resoluciones de carácter jurisdiccional, siempre que estas se traten de sentencias definitivas, o de interlocutorias que pongan término al juicio o hagan imposible su continuación, y que no sean susceptibles de ser impugnadas por medio de otro recurso. De manera excepcional, el

10 Chiovenda, Curso de derecho, $5^{\circ 2 .}$ 
Código autoriza la interposición del recurso de queja en conjunto con el de casación en la forma, cuando se trate de sentencias definitivas dictadas por árbitros arbitradores ${ }^{11}$.

En su inciso segundo, el artículo 545 dispone que la sentencia que acoja un recurso de queja deberá incluir las consideraciones precisas que demuestran la falta o abuso grave que motivó su acogimiento, así como los errores u omisiones manifiestos y graves que los constituyan. Además, deberá indicar las medidas a adoptar para corregir la falta o abuso detectada. Luego la norma agrega que en los casos en que un tribunal invalide una resolución jurisdiccional, este deberá adoptar todas las medidas disciplinarias que estime pertinentes ${ }^{12}$, mientras que debe además dar cuenta al pleno para que adopte medidas disciplinarias adicionales si es que ello fuera procedente. Culmina el artículo señalando que siempre que se acoja un recurso de queja, se deberá amonestar de manera privada al juez o jueces que incurrieron en la falta o abuso, sin perjuicio de la procedencia de otras medidas disciplinarias.

Todo lo anterior es sin perjuicio de la facultad que tiene la Corte Suprema para actuar de oficio cada vez que lo considere pertinente, en ejercicio de sus facultades disciplinarias ${ }^{13}$.

\subsection{Naturaleza del recurso de queja}

Uno de los temas más controvertidos en relación con este recurso es su naturaleza jurídica. La controversia viene dada por el hecho de que no obstante ser un mecanismo para controlar la disciplina de los jueces, el recurso de queja igual faculta al tribunal que conoce de él para modificar lo resuelto por el juez o jueces que cometieron la falta o abuso, lo que le concede también un componente jurisdiccional.

En la doctrina las posiciones se encuentran divididas. Por un lado, autores como Sepúlveda y Oberg señalan que el hecho de que la ley utilice la palabra corregir demuestra un cierto equilibrio entre ambos componentes (jurisdiccional y disciplinario) del recurso: "Al usar

11 Como enseña la doctrina, "conforme a la historia fidedigna de la Ley i9.374, en las discusiones surgidas en las comisiones respectivas se acordó establecer que como respecto de los arbitradores no procede el recurso de casación en el fondo, el recurso de queja sería el único medio de que dispondrán las partes en caso que un árbitro arbitrador falle en forma aberrante, sin respetar los principios de equidad”. Alejandro Romero Seguel y José Ignnacio Díaz Villalobos, El arbitraje interno y comercial internacional (Santiago: Ediciones UC, 20I7), 264.

12 Si bien la norma no contiene una enumeración de dichas medidas, según veremos más adelante lo normal será que ellas se limiten en la práctica a modificar lo resuelto con falta o abuso grave por el tribunal inferior.

13 Según dispone la parte final del inciso primero del artículo 545 del Código. 
la ley el vocablo 'corregir', comprende, a la vez, el elemento sancionatorio y el elemento de enmienda de la decisión jurisdiccional en cuestión” ${ }^{14}$. Otros autores, como Pérez y Núñez, se inclinan por dar mayor relevancia al componente disciplinario que al jurisdiccional - sin perjuicio de describir al de queja como un recurso cuasi jurisdiccional-, al afirmar que "nos encontramos ante un recurso prioritariamente disciplinario" ${ }^{15}$. Por último, encontramos a Tavolari, quien tomando la posición contraria se inclina por ver al recurso de queja como un mecanismo en esencia jurisdiccional, con un componente disciplinario ${ }^{16}$.

En nuestra opinión el recurso de queja es de naturaleza disciplinaria, y tiene un componente jurisdiccional que es limitado y excepcional. Existen distintos argumentos que sustentan dicha posición. En primer lugar, está la historia del recurso. Desde que el mismo fue incorporado en el Código Orgánico de Tribunales, ha tenido por objeto velar por la disciplina de los tribunales de justicia ${ }^{17}$. Asimismo, dentro de los propósitos de la reforma de la que fue objeto el recurso de queja el año 1995, uno muy importante fue reencausar el recurso a su origen disciplinario, luego de su desnaturalización para convertirse en una tercera instancia ${ }^{18}$. En segundo lugar, el texto del artículo 545 del Código dispone claramente que el recurso de queja tiene por exclusiva finalidad corregir las faltas o abusos graves cometidos en la dictación de resoluciones de carácter jurisdiccional, mientras que el artículo 66, inciso tercero del mismo cuerpo legal distingue al recurso de queja de los

14 Flora Sepúlveda Rivas y Héctor Oberg Yáñez, "El recurso de queja”. Revista de Derecho de la Universidad de Concepción I92 (julio-diciembre I994): 8.

15 Álvaro Pérez Ragone y Raúl Núñez Ojeda, Manual de derecho procesal civil: Los medios de impugnación (Santiago: Thomson Reuters, 2015), 497.

16 Señala el autor que "no es posible discutir, en consecuencia, que conviven en la regulación jurídica del recurso, dos naturalezas claramente diferenciables: a) de una parte, una disciplinaria; b) de otra, en cambio, la propiamente impugnadora de resoluciones judiciales o, en esencia jurisdiccional, que es, en definitiva, la que explica el nombre del instituto y el empleo que de él han efectuado [...] En consecuencia - con entera prescindencia de las nomenclaturas y recordando que, especialmente, en derecho, las cosas son lo que son y no como se las denominaexiste una potestad jurisdiccional que se excita por el interesado, a través del recurso de queja y que puede concluir, también, en ejercicio de facultades disciplinarias”. Raúl Tavolari Oliveros, "Procedencia de un recurso de queja ante la Corte Suprema, en contra de fallo dictado por Corte de Apelaciones, conociendo de otro recurso de queja”. Revista de Derecho Procesal de la Facultad de Derecho de la Universidad de Chile 22 (2012): 5०3-5०4.

17 Roberto Munita Herrera, Estudio crítico sobre el recurso de queja (Santiago: Jurídica de Chile, I968), 53 .

18 Cristián Maturana Miquel, Los recursos del Código de Procedimiento Civil en la doctrina y la jurisprudencia. Tomo 2 (Santiago: Thomson Reuters, 20I6), І.о62. 
demás recursos jurisdiccionales. A ello debe agregarse que el Código regula el recurso en comento en su título 16, denominado "De la jurisdicción disciplinaria y de la inspección y vigilancia de los servicios judiciales". En tercer lugar, a diferencia del resto de los recursos jurisdiccionales, el recurso de queja se interpone directamente ante el superior jerárquico de aquel al que se acusa de haber incurrido en una falta o abuso grave, lo que constituye una garantía de que el reclamo llegará ante quien debe conocer del mismo. Por último, el recurso de queja se interpone en contra de una persona (juez) o grupo de personas (jueces), y no en contra de una resolución, lo que lo vuelve a diferenciar de los recursos jurisdiccionales.

Esa naturaleza disciplinaria no se ve alterada por el hecho de que del acogimiento del recurso de queja se siga un acto jurisdiccional de parte del tribunal que lo acogió, y que este modifique en todo o en parte la resolución que motivó el recurso. Es este el componente jurisdiccional limitado y excepcional al que hacíamos referencia.

Parece razonable que, si el superior jerárquico detecta que existe una falta o abuso grave en el actuar de su inferior, adopte las medidas que sean necesarias para corregirlo, aunque de ello se siga una modificación en lo resuelto. La otra alternativa, que nos parece ineficiente, sería que dicho superior jerárquico se limitara a definir si hubo o no una falta o abuso grave y a aplicar la sanción respectiva, para luego devolver la causa al inferior para que emita un nuevo pronunciamiento con jueces distintos. Es más lógico que si el superior ya hizo el esfuerzo de revisar si hubo o no falta o abuso del inferior, aproveche el impulso y modifique lo resuelto, poniendo pronto remedio al mal que se está ocasionando.

\section{3·3. Causal de interposición del recurso de queja}

Según vimos, el artículo 545 del Código Orgánico de Tribunales dispone que el recurso de queja tiene por exclusiva finalidad corregir las faltas o abusos graves cometidas por los tribunales en la dictación de resoluciones de carácter jurisdiccional. De ello se sigue que la causal de procedencia del recurso en comento es la comisión de una falta o abuso grave por parte de un juez o jueces en la dictación de una resolución jurisdiccional.

Algunos autores han intentado dar luces respecto de qué constituiría una falta o abuso grave. Para algunos la falta o abuso a la que se refiere el Código sería el incumplimiento grave de los deberes del juez al resolver el asunto ${ }^{19}$. Otros han señalado como falta o abuso grave el que un juez atente contra la seriedad y el decoro que debe imperar en la administración de justicia, o cuando este abusa de sus facultades discrecionales ${ }^{20}$. También se ha mencionado la infracción, de manera relevante, de una ley $u$ otras normas de derecho ${ }^{21}$.

19 Álvaro Pérez Ragone y Raúl Núñez Ojeda, Manual de derecho procesal, 5 ○2. 
Lo cierto es que hoy la apreciación de las faltas o abusos graves se hace caso a caso y queda sujeta al criterio del tribunal que conoce del recurso. En ese sentido, dentro de las infracciones que con más frecuencia han sido consideradas como faltas o abusos graves encontramos la infracción del texto expreso de la ley ${ }^{22}$; la infracción al derecho a la tutela judicial efectiva ${ }^{23}$; la vulneración de las reglas sobre la competencia ${ }^{24}$ y otras normas procesales; y la afectación del debido proceso, entre otras. Como lo ha resuelto el Máximo Tribunal, el recurso de queja solo procede cuando los errores, omisiones o defectos cometidos por el tribunal, son "manifiestos" y "flagrantes", y por su "alcance y connotación no se compadecen con los contenidos inherentes a la función jurisdiccional” ${ }^{25}$.

Sumado a lo anterior, la jurisprudencia ha incorporado como requisito adicional el denominado "principio de la trascendencia" ${ }^{26}$, en virtud del cual, para que la falta o abuso sea grave, y por lo tanto susceptible de ser denunciada y corregida por medio del recurso de queja, es necesario que ella afecte la resolución de la controversia, que tenga una influencia substancial en lo que se decida. Tal como lo ha señalado la Corte Suprema, es necesario que la falta o abuso tenga una "influencia sustancial, esencial, trascendente en la parte dispositiva de la sentencia" ${ }^{27}$.

Así, cada vez que exista una falta o abuso grave de un tribunal, y dicha falta o abuso grave haya influido en la resolución del asunto, será procedente el recurso de queja, siempre que se cumplan los demás requisitos que establece el legislador para su interposición ${ }^{28}$.

20 Flora Sepúlveda Rivas y Héctor Oberg Yáñez, "El recurso de queja”, II.

21 Gonzalo Calvo Castro, "Algunos aspectos del recurso de queja". Revista de Derecho de la Pontificia Universidad Católica de Valparaíso I (I977): 269.

22 Caso Bravo con Canal, Corte Suprema, rol 2.217-2007, ${ }_{4}$ de julio de 2007.

23 Caso Condominio Doña Isabel con Inspección del Trabajo, Corte Suprema, rol 5.I29-20I7, 9 de mayo de 2017 .

24 Caso Municipalidad de Traiguén con Corte de Apelaciones de Temuco, Corte Suprema, rol 6.916-2008, 5 de mayo de 2009 .

25 Caso Collao con Lam, Corte Suprema, rol ז2.804-2018, i7 de julio de 2018.

26 José Barahona Avendaño, El Recurso de queja: Una interpretación funcional (Santiago: Jurídica de Chile, r998), $4^{\circ}$.

27 Caso Cares con Servicios Edelweis Limitada, Corte Suprema, rol 4.7०9-2017, I7 de mayo de 2017 . En igual sentido se resolvió en caso Lara con Corporación Cultural de Lo Barnechea, Corte Suprema, rol 58.922-20I6, 29 de noviembre de 2016.

28 Contenidos en los artículos 545 y siguientes del Código Orgánico de Tribunales. 


\section{$3 \cdot 4$. Tribunal competente para conocer del recurso de queja}

El tribunal competente para conocer del recurso de queja es el superior jerárquico de aquel que dictó la resolución con falta o abuso grave. De ello se sigue que este recurso será conocido únicamente por las Cortes de Apelaciones y por la Corte Suprema, según lo confirman las normas que se citan a continuación.

Respecto de las Cortes de Apelaciones, el artículo 63 del Código dispone que "las Cortes de Apelaciones conocerán: 1) En única instancia: [...] c) De los recursos de queja que se deduzcan en contra de jueces de letras, jueces de policía local, jueces árbitros y órganos que ejerzan jurisdicción, dentro de su territorio jurisdiccional".

Respecto de la Corte Suprema, su competencia viene dada por los artículos 97 y 98 del Código. El primero de ellos dispone que "las sentencias que dicte la Corte Suprema al fallar los recursos de casación de fondo y forma, de nulidad en materia penal, de queja, de protección y de amparo, así como la revisión de sentencias firmes, no son susceptibles de recurso alguno, salvo el de aclaración, rectificación y enmienda que establece el artículo 182 del Código de Procedimiento Civil". El artículo 98 en tanto señala que "las salas de la Corte Suprema conocerán: [...] 7) De los recursos de queja, pero la aplicación de medidas disciplinarias será de la competencia del tribunal pleno". A ambas normas debe agregarse lo dispuesto en el artículo 82 de la Constitución, que reconoce al Máximo Tribunal la superintendencia directiva, correccional y económica sobre todos los tribunales del país (con excepción del Tribunal Constitucional, el Tribunal Calificador de Elecciones y los tribunales electorales regionales), señalando que, en uso de sus facultades disciplinarias, la Corte Suprema podrá invalidar resoluciones jurisdiccionales en los casos y forma que establezca la ley.

\subsection{Naturaleza jurídica de la resolución en la que se produce la falta o abuso grave}

Dado que el recurso de queja solo procede respecto de faltas o abusos graves cometidas en la dictación de una sentencia definitiva, o de una interlocutoria que pone término al juicio o hace imposible su continuación, para determinar si procede o no la interposición de este recurso lo primero será analizar la naturaleza jurídica de la resolución que se pretende impugnar por vía de recurso de queja.

En ese sentido, un gran porcentaje de los recursos que se declaran inadmisibles lo son porque la resolución en cuestión no admitía su interposición. Así, por ejemplo, encontramos recursos de queja declarados inadmisibles por haber sido interpuestos en contra de una resolución que decretó una medida para mejor resolver ${ }^{29}$; de otra que declaró inadmisible

29 Caso Barki con Vera, Corte Suprema, rol I53-2108, ro de enero de 2018. 
un recurso de apelación incidental ${ }^{30}$, de otra que rechazó un recurso de hecho ${ }^{31}$, de otra que rechazó un recurso de reposición ${ }^{32}$, de otra que rechazó un recurso de nulidad labo$\mathrm{ral}^{33}$, de otra que rechazó un incidente de recusación ${ }^{34}$, de otra que rechazó la solicitud de citar a confesar deuda ${ }^{35}$, de otra que rechazó un recurso de aclaración rectificación o enmienda ${ }^{36}$, de otra que no hizo lugar al recurso de reposición interpuesto contra aquella resolución que declaró desistido un recurso de casación ${ }^{37}$, de otra que declaró desierto un recurso de apelación ${ }^{38}$, de otra que rechazó el incidente de nulidad de todo lo obrado ${ }^{39}$, de otra que confirmó una resolución de primera instancia que acogió la excepción dilatoria de ineptitud del libelo ${ }^{40}$, de otra que confirmó una resolución de primera instancia que concedió una medida precautoria ${ }^{41}$, y de otra que rechazó un incidente de abandono del procedimiento $^{42}$, entre otros casos.

Así, es esencial que la resolución en la que se produzca la falta o abuso grave se encuentre dentro de alguna de las dos categorías que señala expresamente el artículo 545 del Código Orgánico de Tribunales.

Caso Enel Distribución Chile S.A. con Gajardo, Corte Suprema, rol 4ł3-20I8, 23 de enero de 2018.

31 Caso Carrasco con Primer Juzgado de Letras de Melipilla, Corte Suprema, rol 918-2018, 17 de enero de 2018 .

32 Caso Lara con Fisco de Chile, Corte Suprema, rol r.046-20I8, 224 de enero de 2018.

33 Caso Matamala con Chilexpress S.A., Corte Suprema, rol 12.294-20I8, 6 de junio de 2018.

34 Caso Cuello con Llanos, Corte Suprema, rol 38.512-2017, r2 de septiembre de 2017.

35 Caso Sociedad de Montajes con Mopla Construcciones, Corte Suprema, rol 4o.69o-2017, I7 de octubre de 2017 .

36 Caso Polanco con Banco Security, Corte Suprema, rol 43.255-2017, 4 de diciembre de 2017.

37 Caso OHL Concesiones Chile S.A. con SII, Corte Suprema, rol r2.505-20I8, 28 de junio de 2018.

38 Caso Llanos con Salcobrand S.A., Corte Suprema, rol I4.83I-20I8, 4 de julio de $20 \mathrm{I} 8$.

39 Caso Carriel con Áridos y Servicios Segal, Corte Suprema, rol I5.012-20I8, 5 de julio de 2018.

40 Caso QBE Chile Seguros con Concesionaria Costanera Norte, Corte Suprema, rol I6.809-20I8, 30 de julio de 2018.

41 Caso Ziller con Sociedad Santa Carolina Limitada, Corte Suprema, rol Ig.I/43-20I8, I4 de agosto de 2018 .

42 Caso Compañía de Seguros Generales con Nolasco, Corte Suprema, rol 3.69i-2009, in de junio de 2009 . 


\section{NATURALEza DE LA RESOLUCiÓN QUE CONDENA Y REGULA LAS COSTAS}

Entrando ya en el tema que es objeto de este trabajo, lo primero será aclarar la naturaleza jurídica de la resolución que se pronuncia sobre las costas. Al respecto, debemos distinguir entre el pronunciamiento del tribunal que condena en costas, y aquel que determina el monto de las mismas (regulación de costas).

Sobre la condena en costas, esta forma parte de la sentencia que resuelve la cuestión o asunto que fue sometida al conocimiento del tribunal, sea que se trate de la sentencia definitiva del juicio o de una interlocutoria. Como dispone el artículo 144 del Código de Procedimiento Civil, "la parte que sea vencida totalmente en un juicio o en un incidente, será condenada al pago de las costas". Lo anterior, sin embargo, ha llevado a que exista controversia respecto de si la condena en costas tiene la misma naturaleza jurídica de la sentencia en la que se inserta, o bien, una independiente.

En la jurisprudencia existe una clara inclinación por negarle a la condena en costas la misma naturaleza jurídica de la resolución a la que accede, y se prefiere catalogarla como una medida de orden económico, que es independiente de la resolución judicial. En ese sentido, la Corte Suprema resolvió que

es menester señalar en relación a la denuncia de infracción al artículo 147 del Código de Procedimiento Civil que, como ha reiterado uniformemente la doctrina y la jurisprudencia de esta Corte Suprema, la condena en costas no reviste el carácter de sentencia definitiva, pues se trata de una medida de orden económico que no forma parte del asunto controvertido ${ }^{43}$.

Una posición similar mantiene Reyes, al afirmar que "el pronunciamiento en costas, si bien está contenido en el acto jurídico procesal denominado sentencia definitiva, no es asimilable a su contenido, pues no está referida a las acciones y excepciones hechas valer

43 Caso Zelada con Canales, Corte Suprema, rol 5.820-2010, I de septiembre de 2010. En igual sentido se pronunció en la causa Núñez con Municipalidad de Concepción, Corte Suprema, rol 3.5II-20I2, I5 de septiembre de 2010: "Sexto: Que en lo que se refiere a la denuncia que efectúa respecto de la condena en costas por estimar infringido el artículo I 4 del Código de Procedimiento Civil, cabe consignar que la decisión sobre las costas no participa de la naturaleza jurídica de una sentencia definitiva, ya que no pone fin a la instancia resolviendo la cuestión o asunto que ha sido objeto del juicio, ni tiene el carácter de interlocutoria de las que ponen término al juicio o hacen imposible su continuación, de manera que el recurso a este respecto tampoco puede prosperar". Otros ejemplos encontramos en Vera con Miranda (rol $34.262-$ 20I7); Anglo American con Tranex Limitada (rol 5.92I-20I9); y en Banco Falabella con Mujica (rol 4:392-20I8), entre otros. 
en juicio; en otras palabras, las costas están desvinculadas de la resolución del asunto controvertido" ${ }^{\prime 4}$.

No obstante lo anterior, en nuestra opinión la condena en costas sí comparte la naturaleza de la sentencia a la que accede, puesto que forma parte integrante de la misma, al punto que todas las sentencias que se dictan en el país deben contener un pronunciamiento sobre las costas. Así lo confirman los términos imperativos del artículo 144 del Código de Procedimiento Civil ("la parte que sea vencida totalmente en un juicio o en un incidente, será condenada al pago de las costas"), y así se desprende también de las sentencias que día a día se dictan, todas las cuales contienen un pronunciamiento respecto de las costas del proceso. Además, el artículo 445 del Código del Trabajo dispone que "en toda resolución que ponga término a la causa o resuelva un incidente, el juez deberá pronunciarse sobre el pago de las costas del procedimiento, tasando las procesales y regulando las personales, según proceda”, idea que reitera el mismo cuerpo legal en su artículo 459 numeral 7, al enumerar los requisitos de la sentencia.

Al ser obligatorio para el tribunal incluir en sus pronunciamientos una mención y decisión respecto de las costas del juicio, no parece razonable distinguir ese pronunciamiento de la decisión global que se adopta, y asignarle una naturaleza jurídica distinta. Por lo demás, reconocerle a la condena en costas la misma naturaleza jurídica que a la sentencia en la que se incorpora simplifica su impugnación, al no ser necesario enfrascarse en cuestiones de admisibilidad adicionales a las que de todas formas tendrá que enfrentar el recurso interpuesto en contra de la sentencia principal. Por lo tanto, el hecho de que la condena en costas se determine en una sentencia definitiva o en una interlocutoria, determinará la naturaleza jurídica de esa condena.

Respecto de la naturaleza jurídica de la resolución que regula el monto de las costas, creemos que se tratará siempre de una sentencia interlocutoria, por referirse a una cuestión incidental del juicio, que requiere de un pronunciamiento especial del tribunal. En efecto, una vez que se decreta una condena en costas, sea por sentencia interlocutoria o definitiva, acto seguido la parte vencedora debe solicitar al tribunal que regule las costas personales y tase las procesales. La decisión que adopte el tribunal será puesta en conocimiento de las partes, que cuentan con un plazo de tres días para objetarlas (artículo 141 del Código de Procedimiento Civil) ${ }^{45}$. Sobre esa objeción el tribunal podrá pronunciarse de plano o

44 Diego Reyes López, "Posibilidad de impugnar la condena en costas impuesta en la sentencia definitiva de los procedimientos laborales chilenos". Revista Chilena de Derecho del Trabajo y de la Seguridad Social 4, n. $^{\circ} 8$ (2013): 93.

45 Este plazo corre tanto para la parte vencida, si considera que las costas son muy altas, como también para la vencedora, si las considera muy bajas. 
darle traslado a la parte contraria (artículo 142), lo que confirma que la regulación de costas constituye un incidente, y la resolución que lo resuelve tiene el carácter de sentencia interlocutoria (artículo 158).

\section{PROCEDENCIA DEL RECURSO DE QUEJA RESPECTO DE LA CONDENA Y REGULA- CIÓN DE LAS COSTAS}

Dicho lo anterior, ahora se abordará la interrogante principal de este trabajo, que consiste en definir si procede o no la interposición del recurso de queja tanto en contra de la condena en costas, como de la regulación de las mismas. Para ambos casos se parte de la base de que ha existido una falta o abuso grave de parte del tribunal.

\section{I. Procedencia del recurso de queja en relación con la condena en costas}

Al dictar la sentencia definitiva de un juicio, o la interlocutoria en un incidente, el tribunal debe condenar en costas a la parte que resultó completamente vencida, a menos que concluya que a pesar de su total derrota, tuvo motivos plausibles para litigar. Dado que esa condena en costas va inserta dentro de la sentencia, creemos que ambas, condena en costas y sentencia, comparten la misma naturaleza jurídica.

De lo anterior se sigue que la impugnación de la condena en costas podrá hacerse de la misma forma en que se impugne la sentencia en la que ella está inserta. Así lo permite expresamente el artículo 145 del Código de Procedimiento Civil, que dispone que "podrá el tribunal de segunda instancia eximir de las costas causadas en ella a la parte contra quien se dicte la sentencia, sea que mantenga o no las que en primera instancia se hayan impuesto, expresándose en este caso los motivos especiales que autoricen la exención”. Por ejemplo, si se promueve un incidente de nulidad por incompetencia del tribunal, y el mismo es rechazado en todas sus partes con costas, la parte que lo promovió y resultó vencida, probablemente interpondrá un recurso de apelación en contra de la sentencia, intentando que se declare la incompetencia, y, además, que sea revocada la condena en costas que le fue aplicada.

Sin embargo, el hecho de que la condena en costas siga la suerte de la sentencia a la que accede, implica que la parte afectada con la sentencia y las costas probablemente tendrá otros medios para impugnar tales decisiones, lo que implica que el recurso de queja no será procedente. Ello, puesto que según se explicó, otro de los requisitos de procedencia que establece el artículo 545 consiste en que no existan otros recursos ordinarios o extraordinarios en contra de la sentencia en la que se cometió la falta o abuso.

La única posibilidad es que dicha condena en costas esté inserta en una sentencia que no sea susceptible de ningún otro recurso, como sucede, por ejemplo, con las sentencias definitivas dictadas en segunda instancia por las Cortes de Apelaciones, en las causas de 
competencia de los juzgados de policía local. En ese sentido, existen fallos de la Corte Suprema en los que se han acogido recursos de queja interpuestos en contra de jueces que condenaron en costas sin que fuera procedente hacerlo.

Cuarto: Que, en tales condiciones, los sentenciadores conculcaron el tenor expreso del artículo 146 del Código de Procedimiento Civil, que impide condenar al pago de costas cuando se hayan emitido, por los jueces que concurran al fallo en un tribunal colegiado, uno o más votos favorables a la parte que pierde el asunto debatido que es precisamente lo acontecido en la especie respecto de la recurrente, que tuvo a su favor el voto del ministro Juan Cristóbal Mera Muñoz, quien fue de opinión de confirmar el edicto apelado, por sus propios fundamentos. Tal omisión constituye una falta grave, dado que de haber considerado la regla cuya preferencia se reclama, en los términos que manda la ley, deberían haber prescindido de la imposición de las costas al demandante, sin que sean atendibles las razones dadas por el recurridos en su informe, ya que no se condicen con el ejercicio de la función jurisdiccional de un tribunal superior de justicia ${ }^{46}$.

Otra hipótesis de procedencia del recurso de queja en estas circunstancias, tendría lugar cuando una Corte de Apelaciones dicte una sentencia definitiva, y dicha sentencia no incurra en ningún vicio de los que haría procedente los medios de impugnación jurisdiccionales establecidos en la ley, por lo que sería el único agravio la falta o abuso grave cometida al condenar en costas. En ese escenario, en que no existen otros recursos disponibles, también sería procedente el recurso de queja en contra de la declaración de condena en costas. En ese sentido, una situación particular tuvo lugar el año 2018, cuando la Corte Suprema acogió a trámite un recurso de queja interpuesto en contra de los ministros del Tribunal de Cuentas de Segunda Instancia de la Contraloría General de la República, a pesar de que la resolución dictada por dichos jueces era susceptible de ser impugnada por el recurso especial de revisión establecido en el artículo 126 de la Ley 10.336. El fundamento de dicha admisibilidad fue que el recurso de revisión es un recurso extraordinario que procede solo en algunas hipótesis, ninguna de las cuales se configuraba en la causa en cuestión $^{47}$. Lo mismo podría sostenerse respecto de otros recursos, como los de casación, en casos en los que el único vicio de la sentencia sea la determinación abusiva de las costas.

En conclusión, de lo dicho en este apartado se puede concluir que la procedencia del recurso de queja en contra de la declaración de condena en costas, dependerá de que ese recurso sea procedente respecto de la resolución en la que va inserta dicha condena.

46 Caso Hidalgo con Piamonte S.A., Corte Suprema, rol 4.92I-2009, I6 de noviembre de 2009. En igual sentido, caso Enap Refinerías S.A. con Constructora Comsa, Corte Suprema, rol 3.984-2013, 5 de noviembre de 2013 .

47 Caso Ferrada y otros con Contraloría, Corte Suprema, rol 7·427-20I8, ${ }_{4}$ de octubre de 2018. 


\subsection{Procedencia del recurso de queja en relación con la regulación de las costas}

Hoy existe un criterio mayoritario - por no decir absoluto- de la Corte Suprema de oponerse a la procedencia del recurso de queja en contra del juez o jueces que regularon las costas, principalmente por entender que dicha resolución no comparte la naturaleza jurídica que exige el artículo 545 del Código Orgánico de Tribunales para la procedencia del recurso. A continuación, citamos algunos ejemplos recientes.

2) Que en la especie el libelo incoado por el abogado XX., en autos de la Corte de Apelaciones de Punta Arenas rol 182-2018, lo ha sido respecto de una resolución que confirmó con declaración aquella de primer grado que fijó las costas personales de ese juicio. 3) Que de lo expuesto se desprende que la resolución aludida en el motivo que precede no es de aquellas que permiten la interposición de un recurso de queja en su contra, puesto que no participa de la naturaleza de las señaladas en el primer acápite, a consecuencia de lo cual solo cabe concluir que el recurso deducido no puede ser admitido a tramitación ${ }^{48}$.

Segundo: Que la resolución que se impugna en estos antecedentes es aquella que rechazó la objeción a las costas personales reguladas; la que no participa de la naturaleza jurídica antes indicada, razón suficiente para declarar inadmisible el recurso intentado en autos ${ }^{29}$.

2) Que en la especie el libelo incoado por don MM, en autos de la Corte de Apelaciones de Chillán rol 1-2016, lo ha sido respecto de una resolución que confirmó aquella de primer grado que fijó en la suma de \$9.000.000 las costas personales de ese juicio. 3) Que de lo expuesto, se desprende que la resolución aludida en el motivo que precede no es de aquellas que permiten la interposición de un recurso de queja en su contra, puesto que no participa de la naturaleza de las señaladas en el primer acápite, a consecuencia de lo cual solo cabe concluir que el recurso deducido no puede ser admitido a tramitación ${ }^{50}$.

Como podemos apreciar, la razón por la que la Corte Suprema ha rechazado la procedencia del recurso de queja en contra de los jueces que dictaron la resolución regulando las costas, es que esa resolución no tiene la naturaleza que exige el Código Orgánico de Tribunales para la procedencia de este recurso. Es decir, no se trataría de una sentencia definitiva, o de una interlocutoria que pone término al juicio o hace imposible su continuación.

\footnotetext{
48 Caso Montt con Radich, Corte Suprema, rol 26.55I-20I8, 5 de noviembre de 2018.

49 Caso Rojas con Banco Santander, Corte Suprema, rol 9.๑54-20I8, II de mayo de 20I7.

50 Caso Guíñez con Díaz, Corte Suprema, rol I4.854-20I6, 3 de marzo de 2016.
} 
Coincidimos con ese criterio. Si bien consideramos que la resolución por la que una Corte de Apelaciones se pronuncia sobre la objeción de las costas tiene la naturaleza de sentencia interlocutoria, es innegable que la misma no pone término al juicio ni hace imposible su continuación. Es más, a esas alturas el juicio al que se refiere la condena en costas ya se encontrará terminado, por lo que quedaría pendiente solo la ejecución del fallo. Por lo tanto, estamos de acuerdo con la postura de la Corte Suprema de que el recurso de queja es inadmisible cuando se interpone en contra de los ministros de Cortes de Apelaciones que se pronunciaron respecto de una objeción a la regulación de las costas finales del juicio.

Sin embargo, existe una situación particular que nos impide quedarnos tranquilos con la conclusión anterior, y que se refiere a la posibilidad de que los ministros de una Corte de Apelaciones, al pronunciarse en segunda instancia respecto de la objeción de la regulación de costas, cometan una falta o abuso grave que afecte de forma significativa los derechos de alguna de las partes, en concreto, al imponer una sanción de costas que sea claramente desproporcionada, o que no se condiga con la realidad del juicio a la que ella accede.

Creemos que, en tales casos, sería necesario que la Corte Suprema pudiera conocer del asunto y eventualmente corregir la avaluación de las costas, si estima que en su determinación se produjo una falta o abuso grave. Existen distintas razones que así lo recomiendan. En primer lugar, está el carácter de sanción que tiene la condena en costas. No parece razonable que una sanción pueda ser aplicada por un tribunal sin ningún tipo de control, especialmente si la misma involucra importantes cantidades de dinero, como ha ocurrido en ciertas ocasiones en el último tiempo. Sumado a lo anterior, el hecho de que el legislador haya entregado la regulación de las costas personales a la prudencia del tribunal, no implica que esa prudencia pueda ser ejercida de manera arbitraria, ni que esté a salvo de ser revisada con posterioridad. Sobre todo si con esa prudencia se cometieron faltas o abusos graves en contra de alguna de las partes del proceso - en especial de la parte vencida que resultó condenada, que podrá verse expuesta a pagar importantes sumas de dinero por concepto de costas mal reguladas-. Creemos que el entregar una mayor libertad a un tribunal exige ir acompañado de mecanismos de control y corrección para el caso en que esa libertad sea utilizada de forma inadecuada. Finalmente, y relacionado con ambos aspectos anteriores, encontramos que el artículo 82 de la Constitución entrega a la Corte Suprema la superintendencia directiva, correccional y económica respecto de (casi) todos los tribunales del país, y que, entre otras cosas, le exige velar por la disciplina de esos tribunales. Por lo tanto, si en el ejercicio prudencial que les entrega el legislador, los ministros de una Corte de Apelaciones aplican una sanción en costas con falta o abuso grave, y de ella se sigue un perjuicio de relevancia para alguna de las partes - sobre todo para la parte vencida-, la Corte Suprema tiene la obligación de conocer el asunto, y adoptar las medidas que estime pertinentes, en caso de que efectivamente se haya configurado una falta o abuso grave. 
La pregunta que toca responder ahora es cómo se debe materializar dicha revisión del Máximo Tribunal, atendido que el recurso de queja es inadmisible. Creemos que la respuesta la entregan el Código de Procedimiento Civil y el Código Orgánico de Tribunales, cada uno de los cuales contiene una herramienta que a nuestro juicio permite a la Corte Suprema conocer de la falta o abuso grave en estos casos, aun al ser inadmisible el recurso de queja.

La primera consiste en el ejercicio de las facultades disciplinarias que le reconoce de forma expresa el inciso primero del artículo 545, que dispone que

el recurso de queja tiene por exclusiva finalidad corregir las faltas o abusos graves cometidos en la dictación de resoluciones de carácter jurisdiccional. Solo procederá cuando la falta o abuso se cometa en sentencia interlocutoria que ponga fin al juicio o haga imposible su continuación o definitiva, y que no sean susceptibles de recurso alguno, ordinario o extraordinario, sin perjuicio de la atribución de la Corte Suprema para actuar de oficio en ejercicio de sus facultades disciplinarias.

Precisamente, a través del ejercicio de esta facultad es que el Máximo Tribunal, con bastante frecuencia, interviene de oficio en asuntos en los que de otra forma no podría hacerlo, por no existir medios de impugnación a disposición de las partes para presentárselos. En efecto, de la revisión de la jurisprudencia de la Corte Suprema quedan al descubierto muchos casos en los que si bien declara inadmisibles los recursos de queja, acto seguido, en la misma sentencia, procede a conocer de oficio de la situación denunciada, para finalmente corregirla.

Así sucedió en la causa RSA Seguros con Figueroa ${ }^{51}$, en que la Corte Suprema si bien declaró inadmisible el recurso de queja interpuesto en contra de los ministros de una Corte de Apelaciones, acto seguido, actuando de oficio y en ejercicio de sus facultades disciplinarias, invalidó la sentencia dictada por esos ministros acogiendo un recurso de queja interpuesto en contra de un árbitro arbitrador, por haber interpretado de manera incorrecta una norma. El Máximo Tribunal resolvió que, "en consecuencia, al acoger el recurso de queja que se viene comentando, la señora ministra y el señor abogado integrante que conformaron el voto de mayoría han incurrido en una falta grave que debe corregirse en virtud de las facultades correcciones que la constitución y la ley le confieren a esta Corte”.

51 Caso RSA Seguros con Figueroa, Corte Suprema, rol 2.406-2013, 5 de agosto de 2013. 
Otro ejemplo lo encontramos en la causa Municipalidad de Las Condes con Secretaría Ministerial de Vivienda y Urbanismo ${ }^{52}$, en la que una Corte de Apelaciones erróneamente declaró desierto un recurso de apelación porque la apelante no compareció dentro del plazo que establecía el Código de Procedimiento Civil para hacerse parte en segunda instancia. En esa oportunidad la afectada interpuso un recurso de queja, el cual fue declarado inadmisible por la Corte Suprema, la que, sin embargo, procedió en la misma sentencia a actuar de oficio y dejar sin efecto la resolución de la Corte, ordenando en su reemplazo que el recurso de apelación que había sido declarado inadmisible fuera puesto en relación.

La otra alternativa para que el Máximo Tribunal pueda conocer de las faltas o abusos graves cometidos en la regulación de las costas consiste en el ejercicio de las facultades de corrección del procedimiento que el Código de Procedimiento Civil le reconoce a todos los tribunales, en sus artículos 83 inciso primero, y 84 inciso final. Esta figura también ha tenido aplicación en la práctica, por ejemplo en la causa Readi con Adaui ${ }^{53}$, la Corte Suprema declaró inadmisible un recurso de queja, pero acto seguido procedió a invalidar todo lo obrado en un procedimiento arbitral que había demorado más de cuatro años, porque el árbitro actuó en él con facultades de arbitrador, aunque las partes en el compromiso le habían otorgado las de árbitro de derecho: "Siendo así, el tribunal ejercerá las facultades oficiosas de que está dotado de conformidad a lo prevenido en el inciso final del artículo 84 del Código de Procedimiento Civil e invalidará todo lo obrado en el expediente arbitral pues ha sido tramitado por un juez que obró en una calidad que en derecho no le correspondía". Un caso similar encontramos en la causa Neira con Prat ${ }^{54}$, cuando en el ejercicio de estas mismas facultades, la Corte Suprema procedió a invalidar de oficio una resolución por la que erróneamente se había declarado inadmisible por extemporáneo un recurso de casación en la forma: "Ante la equivocación que ha quedado al descubierto, esta Corte hará uso de la facultad contenida en el acápite final del artículo 84 del Código de Procedimiento Civil”.

Confirman lo anterior una serie de fallos que ha dictado la Corte Suprema en relación a recursos de queja interpuestos en contra de ministros de Cortes de Apelaciones, en los que se ha denunciado que la fianza de resultas establecida por ellos para permitir la ejecución de una sentencia impugnada de casación, no es suficiente para cumplir con su finalidad cautelar. Esto es importante, puesto que tal como ocurre con la fijación de las costas, en estos casos también estamos frente a una cuantificación en dinero por parte de un tribunal de alzada, efectuada por medio de una resolución que por su naturaleza no

\footnotetext{
52 Caso Municipalidad de Las Condes con Secretaría Ministerial de Vivienda y Urbanismo, Corte Suprema, rol 8.9I9-20I8, 9 de agosto de 2018.

53 Caso Readi con Adaui, Corte Suprema, rol I9.I/2-20I8, 22 de enero de 20I9.

54 Caso Neira con Prat, Corte Suprema, rol 3.425-20I3, 20 de agosto de $20 \mathrm{I} 3$.
} 
admite la interposición del recurso de queja. Pues bien, en muchos de esos casos el Máximo Tribunal adopta el mismo camino que ya hemos señalado, al declarar inadmisibles o rechazando los recursos de queja, para luego modificar de oficio el monto de las fianzas ${ }^{55}$.

En conclusión, el hecho de que el recurso de queja sea inadmisible para impugnar la regulación de las costas por parte de una Corte de Apelaciones, no obsta a que dicho ejercicio pueda de todos modos ser sometido al conocimiento de la Corte Suprema, en caso de que en él se haya cometido una falta o abuso grave. Dicho control, según se explicó, deberá materializarse por medio del conocimiento de oficio de la situación, ya sea en el ejercicio de las facultades disciplinarias que el artículo 545 del Código Orgánico de Tribunales reconoce al Máximo Tribunal, o de la facultad correctiva del procedimiento que se encuentra consagrada en los artículos 83 y 84 inciso final del Código de Procedimiento Civil.

\section{UN CASO PRÁCTICO QUE REFLEJA LA IMPORTANCIA DEL ASUNTO EN ESTUDIO}

Para terminar, se expone un caso que fue recientemente revisado por la Corte Suprema ${ }^{56}$, que confirma la necesidad de que esta asuma un rol activo en aquellos casos excepcionales en los que un tribunal de segunda instancia aplique una condena en costas que parezca ser excesiva o desproporcionada.

El año 2014, una compañía minera inició un arbitraje ante el Centro de Arbitraje y Mediación de la Cámara de Comercio de Santiago, en contra de una empresa contratista. Al término de la primera instancia, el árbitro dictó sentencia definitiva rechazando en todas sus partes la demanda, lo que liberó eso sí a la demandante del pago de las costas, por considerar que tuvo motivos plausibles para litigar. En contra de dicha sentencia se alzaron en apelación ambas partes, lo que debió ser resuelto por un panel arbitral de segunda instancia. En su sentencia, el panel confirmó la sentencia en todas sus partes, pero modificó lo resuelto en relación con las costas, por lo que condenó a la empresa demandante a su pago, por haber resultado enteramente vencida.

De vuelta el expediente en primera instancia, y al solicitarse el cumplimiento incidental del fallo, la parte victoriosa solicitó que se tasaran las costas personales del arbitraje, suma que fue fijada por el juez árbitro en 1.000 UF. La parte vencedora en el proceso objetó dichas costas, y solicitó que las mismas fueran elevadas a la suma de \$ 600 millones.

55 Algunos ejemplos encontramos en los casos Empresa Minera Meridian Limitada con Ministros de la Corte de Apelaciones de Santiago (rol 88.984-2016); Alfredo Waugh Correa y otro con Ministros de la Corte de Apelaciones de Valdivia (rol 9.147-2015); y Codelco Chile División Andina

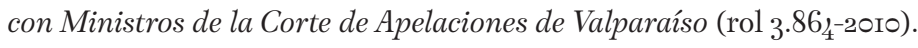

56 Todos los antecedentes a los que se hace mención están acompañados en la causa Anglo American Sur S.A. con Tranex Limitada. 
Dicha pretensión fue rechazada por falta de pruebas. En contra de ese rechazo, la parte vencedora interpuso un recurso de apelación, que fue conocido por el panel arbitral de segunda instancia, el que luego de revisar el asunto resolvió modificar de manera sustancial dicha regulación, aumentándola desde las 1.000 UF originales (\$27 millones a esa fecha), a 15.500 UF (\$ 426 millones a esa fecha). Es decir, multiplicó en más de 1.550\% la condena en costas regulada en primera instancia, imponiendo a la demandante una sanción sin precedentes en nuestro ordenamiento jurídico.

La resolución del panel arbitral fue la siguiente:

Que no habiendo XX acompañado oportunamente antecedentes que justifiquen el monto de \$ 600 millones que ahora reclama, corresponde que este tribunal arbitral tase las costas personales de acuerdo a su criterio para cuyo efecto ha considerado que la cuantía de la demanda interpuesta por NN asciende a doce mil millones de pesos, que el proceso judicial iniciado por dicha demanda duró 43 meses, incluyendo dos instancias procesales además del recurso de casación ante la Excma. Corte Suprema, la complejidad de la materia debatida, que incluyó más de una decena de incumplimientos contractuales imputados a la demandada y la extensa prueba rendida, que incluyó, entre otros medios de prueba, la declaración de más de cuatro decenas de testigos, 17.000 vales de control diario, las planillas de web control correspondientes a los años 2011, 2012, 2013 y 2014, los informes emitidos por DICTUM, IDIEM, Econsult y KPMG y el informe pericial emitido por el perito designado por el tribunal de primera instancia, Se resuelve: Revocar la sentencia interlocutoria apelada en la parte que rechaza la objeción formulada por $\mathrm{XX}$ a la tasación de costas personales que consta de la resolución de 2 de agosto de 2018, acoger dicha objeción y regular las costas personales en la suma equivalente en pesos a quince mil quinientas unidades de fomento.

En contra de dicha sentencia, la parte demandante - y condenada en costas - interpuso un recurso de queja ante la Corte Suprema ${ }^{57}$, denunciando como falta o abuso grave la imposición de una condena en costas absolutamente desproporcionada, y que excedía con creces los estándares normales de nuestro medio. Dicho recurso de queja fue finalmente declarado inadmisible, fundado en que la resolución en cuestión no cumplía con la naturaleza exigida por el Código Orgánico de Tribunales para la procedencia del recurso. Sin embargo, resulta relevante el que la Corte Suprema antes de desestimarlo pidiera informe a los jueces recurridos de queja, puesto que ello confirma que revisó el fondo del asunto, y que, si hubiera considerado que existió una falta o abuso grave, posiblemente habría actuado de oficio y la habría corregido.

\footnotetext{
57 Anglo American Sur S.A. con Tranex Limitada.
} 
Si bien no pretendemos adentrarnos en las circunstancias propias del caso, por exceder el objetivo de este trabajo, el mismo nos parece relevante para demostrar la importancia que tiene que en ciertas ocasiones excepcionales, la Corte Suprema pueda conocer y pronunciarse respecto del monto que se fijó como condena en costas. En casos como este, en el que prudencialmente se condenó a una parte a pagar más de \$ 420 millones en costas, luego de que el tribunal arbitral que conoció en primera instancia del asunto las tasara en cerca de $\$ 27$ millones, parece razonable que a la parte condenada se le permita al menos la posibilidad de presentarle su caso al Máximo Tribunal, y que este decida si la condena fue adecuada o no. El hecho de que el recurso de queja no sea admisible no libera a la Corte Suprema de revisar y corregir las faltas o abusos graves que se pudieran cometer en la regulación de las costas del juicio.

\section{CONCLUSIÓN}

Dentro de las costas que considera nuestro ordenamiento, las más relevantes son las personales. No solo por su cuantía - que muchas veces alcanzan los varios millones de pesos-, sino además porque las mismas son determinadas de manera discrecional por los tribunales, sin que exista en nuestra legislación algún estándar o parámetro al que ellos deban atenerse. Es esa discrecionalidad la que exige que bajo ciertos supuestos el monto de las costas pueda ser revisado por la Corte Suprema.

Respecto de la forma de elevar el asunto al Máximo Tribunal, hemos demostrado la improcedencia del recurso de queja, toda vez que la resolución que determina o confirma el monto de las costas no tiene la naturaleza que exige el Código Orgánico de Tribunales para la procedencia de este recurso. Es decir, no se trata de una sentencia definitiva, o de una interlocutoria que pone término al juicio o hace imposible su continuación.

Sin embargo, el hecho de que el recurso de queja sea inadmisible para impugnar la regulación de las costas por parte de una Corte de Apelaciones, no libera a la Corte Suprema de revisar y corregir las faltas o abusos graves que se pudieran cometer en la regulación de las costas del juicio. Ese control debe existir, y deberá materializarse por medio del conocimiento de oficio de la situación, ya sea en el ejercicio de las facultades disciplinarias que el artículo 545 del Código reconoce al Máximo Tribunal, o de la facultad correctiva del procedimiento que se encuentra consagrada en los artículos 83 y 84 inciso final del Código de Procedimiento Civil. 


\section{BIBLIOGRAFÍA}

- Anabalón Sanderson, Carlos. Tratado práctico de derecho procesal civil chileno. Santiago: Ediciones Universidad de Chile, 1944.

- Barahona Avendaño, José. El recurso de queja: Una interpretación funcional. Santiago: Jurídica de Chile, 1998.

- Calvo Castro, Gonzalo. "Algunos aspectos del recurso de queja". Revista de Derecho de la Pontificia Universidad Católica de Valparaíso 1 (1977): 267-291.

- Chiovenda, José. Curso de derecho procesal civil. Ciudad de México: Harla, 1997.

- Maturana Miquel, Cristián. Los recursos del Código de Procedimiento Civil en la doctrina y la jurisprudencia. Tomo 2. Santiago: Thomson Reuters, 2016.

- Munita Herrera, Roberto. Estudio crítico sobre el recurso de queja. Santiago: Jurídica de Chile, 1968.

- Pérez Ragone, Álvaro y Raúl Núñez Ojeda. Manual de derecho procesal civil: Los medios de impugnación. Santiago: Thomson Reuters, 2015.

- Reyes López, Diego. "Posibilidad de impugnar la condena en costas impuesta en la sentencia definitiva de los procedimientos laborales chilenos". Revista Chilena de Derecho del Trabajo y de la Seguridad Social 4, n. ${ }^{\circ} 8$ (2013): 85-98.

- Romero Seguel, Alejandro. Curso de derecho procesal civil: La acción y la protección de los derechos. 3. ${ }^{\mathrm{a}}$ edición. Santiago: Thomson Reuters, 2017.

- Romero Seguel, Alejandro y José Ignacio Díaz Villalobos. El arbitraje interno y comercial internacional. $2 .^{\text {a }}$ edición. Santiago: Ediciones UC, 2017.

- Sepúlveda Rivas, Flora y Héctor Oberg Yáñez. "El recurso de queja". Revista de Derecho de la Universidad de Concepción 192 (julio-diciembre 1994): 7-22.

- Tavolari Oliveros, Raúl. "Procedencia de un recurso de queja ante la Corte Suprema, en contra de fallo dictado por Corte de Apelaciones, conociendo de otro recurso de queja”. Revista de Derecho Procesal de la Facultad de Derecho de la Universidad de Chile 22 (2012): 499-508. 
JOSÉ A. ALLENDE. - PROCEDENCIA DEL RECURSO DE QUEJA RESPECTO ...

- Valiño Arcos, Alejandro. "Algunos aspectos relacionados con la imposición de costas en el proceso civil en el derecho comparado". Revista Chilena de Derecho 29, n. ${ }^{\circ} 1$ (2002): 147-161. 


\section{JURISPRUDENCIA CITADA}

- Alfredo Waugh Correa y otro con Ministros de la Corte de Apelaciones de Valdivia. Corte Suprema, rol 9.147-2015, 27 de octubre de 2015.

- Anglo American Sur S.A. con Tranex Limitada. Corte Suprema, rol 5.921-2019, 22 de abril de 2019.

- Banco Falabella con Mujica. Corte Suprema, rol 4.392-2018, 26 de junio de 2018.

- Barki con Vera. Corte Suprema, rol 153-2108, 10 de enero de 2018.

- Bravo con Canal. Corte Suprema, rol 2.217-2007, \& de julio de 2007.

- Cares con Servicios Edelweis Limitada. Corte Suprema, rol 4.709-2017, 17 de mayo de 2017.

- Carrasco con Primer Juzgado de Letras de Melipilla. Corte Suprema, rol 918-2018, 17 de enero de 2018.

- Carriel con Áridos y Servicios Segal. Corte Suprema, rol 15.012-2018, 5 de julio de 2018.

- Codelco Chile División Andina con Ministros de la Corte de Apelaciones de Valparaíso. Corte Suprema, rol 3.864-2010, 18 de agosto de 2010.

- Collao con Lam. Corte Suprema, rol 12.804-2018, 17 de julio de 2018.

- Compañia de Seguros con Nolasco. Corte Suprema, rol 3.691-2009, 11 de junio de 2009.

- Condominio Doña Isabel con Inspección del Trabajo. Corte Suprema, rol 5.129-2017, 9 de mayo de 2017.

- Cuello con Llanos. Corte Suprema, rol 38.512-2017, 12 de septiembre de 2017.

- Empresa Minera Meridian Limitada con Ministros de la Corte de Apelaciones de Santiago. Corte Suprema, rol 88.984-2016, 2 de marzo de 2017.

- Enap Refinerías S.A. con Constructora Comsa. Corte Suprema, rol 3.984-2013, 5 de noviembre de 2013.

- Enel Distribución Chile S.A. con Gajardo. Corte Suprema, rol 443-2018, 23 de enero de 2018. 
- Ferrada y otros con Contraloría. Corte Suprema, rol 7.427-2018, 4 de octubre de 2018.

- Guínez con Díaz. Corte de Apelaciones de Chillán, rol 62-2012,1 de octubre de 2012.

- - Corte Suprema, rol 14.854-2016, 3 de marzo de 2016.

- Hidalgo con Piamonte S.A. Corte Suprema, rol 4.921-2009, 16 de noviembre de 2009.

- La Rosa de Sofruco con Exportadora. Juzgado de Letras de Colina, rol C-337-2014, 21 de agosto de 2017.

- Lara con Corporación Cultural de Lo Barnechea. Corte Suprema, rol 58.922-2016, 29 de noviembre de 2016.

- Lara con Fisco de Chile. Corte Suprema, rol 1.046-2018, 24 de enero de 2018.

- Llanos con Salcobrand S.A. Corte Suprema, rol 14.831-2018, 4 de julio de 2018.

- Matamala con Chilexpress S.A. Corte Suprema, rol 12.294-2018, 6 de junio de 2018.

- Montt con Radich. Corte Suprema, rol 26.551-2018, 5 de noviembre de 2018.

- Municipalidad de Las Condes con Secretaría Ministerial de Vivienda y Urbanismo. Corte Suprema, rol 8.919-2018, 9 de agosto de 2018.

- Municipalidad de Traiguén con Corte de Apelaciones de Temuco. Corte Suprema, rol 6.916-2008, 5 de mayo de 2009.

- Neira con Prat. Corte Suprema, rol 3.425-2013, 20 de agosto de 2013.

- Núñez con Municipalidad de Concepción. Corte Suprema, rol 3.5112012, 15 de septiembre de 2010.

- OHL Concesiones Chile S.A. con SII. Corte Suprema, rol 12.505-2018, 28 de junio de 2018.

- Polanco con Banco Security. Corte Suprema, rol 43.255-2017, 4 de diciembre de 2017.

- QBE Chile Seguros con Costanera Norte. Corte Suprema, rol 16.8092018, 30 de julio de 2018.

- Readi con Adaui. Corte Suprema, rol 19.142-2018, 22 de enero de 2019. 
REVISTA DE DERECHO APLICADO LLM UC • NÚMERO 4 • DICIEMBRE 2019

- Rojas con Banco Santander. Corte Suprema, rol 9.054-2018,11 de mayo de 2017.

- RSA Seguros con Figueroa. Corte Suprema, rol 2.406-2013, 5 de agosto de 2013.

- Sociedad de Montajes con Mopla Construcciones. Corte Suprema, rol 40.690-2017, 17 de octubre de 2017.

- Vera con Miranda. Corte Suprema, rol 34.262-2017, 5 de abril de 2018.

- Zelada con Canales. Corte Suprema, rol 5.820-2010,1 de septiembre de 2010.

- Ziller con Sociedad Santa Carolina Limitada. Corte Suprema, rol 19.143-2018, 14 de agosto de 2018. 